\title{
INSECTS
}

\section{GOLDENROD GALLS}

DON BUCKLE, 620 Albert Avenue, Saskatoon, SK S7N 1 G7

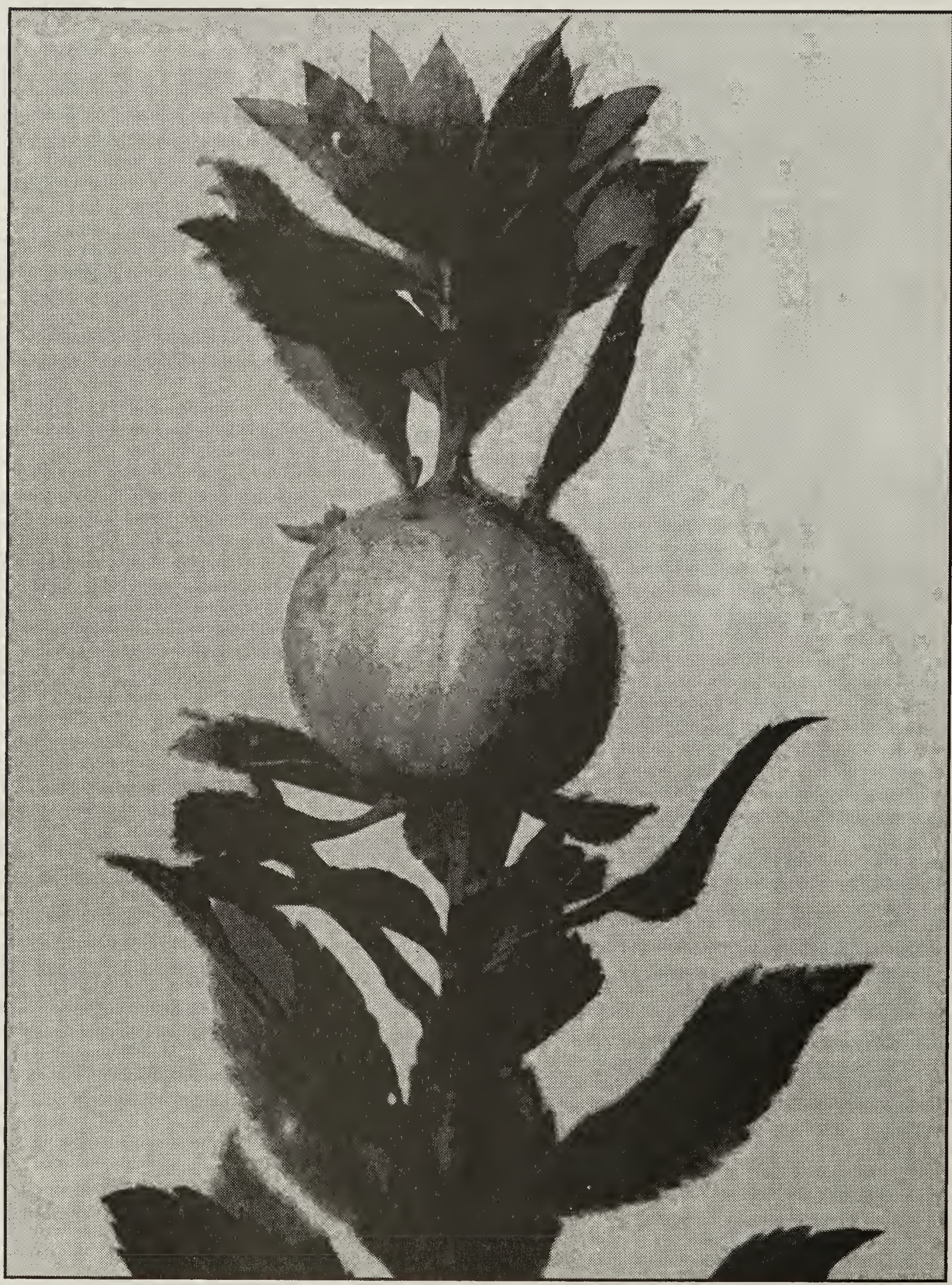


Yellow banks of goldenrod in bloom are the signature of autumn here in Saskatchewan. The Canada Goldenrod, Solidago canadensis, is common in the meadows and waste places of the Aspen Parkland. Stop for a close look at a patch of these and you will likely see round swellings on their stems (Fig. 1). What are they? Many years ago my curiosity was aroused. A quick search of the literature (it was then the 1970s) revealed little more than that they were galls made by the Goldenrod Gall Fly, Eurosta solidaginsis, which belongs to the fruit fly family Tephritidae. Over the next few years, I collected goldenrod galls, opened them at various times of the year, and reared their occupants. Little by little, details of this surprisingly complex little universe were revealed for my entertainment.

Adult Goldenrod Gall Flies emerge from the previous year's galls (Fig. 2)

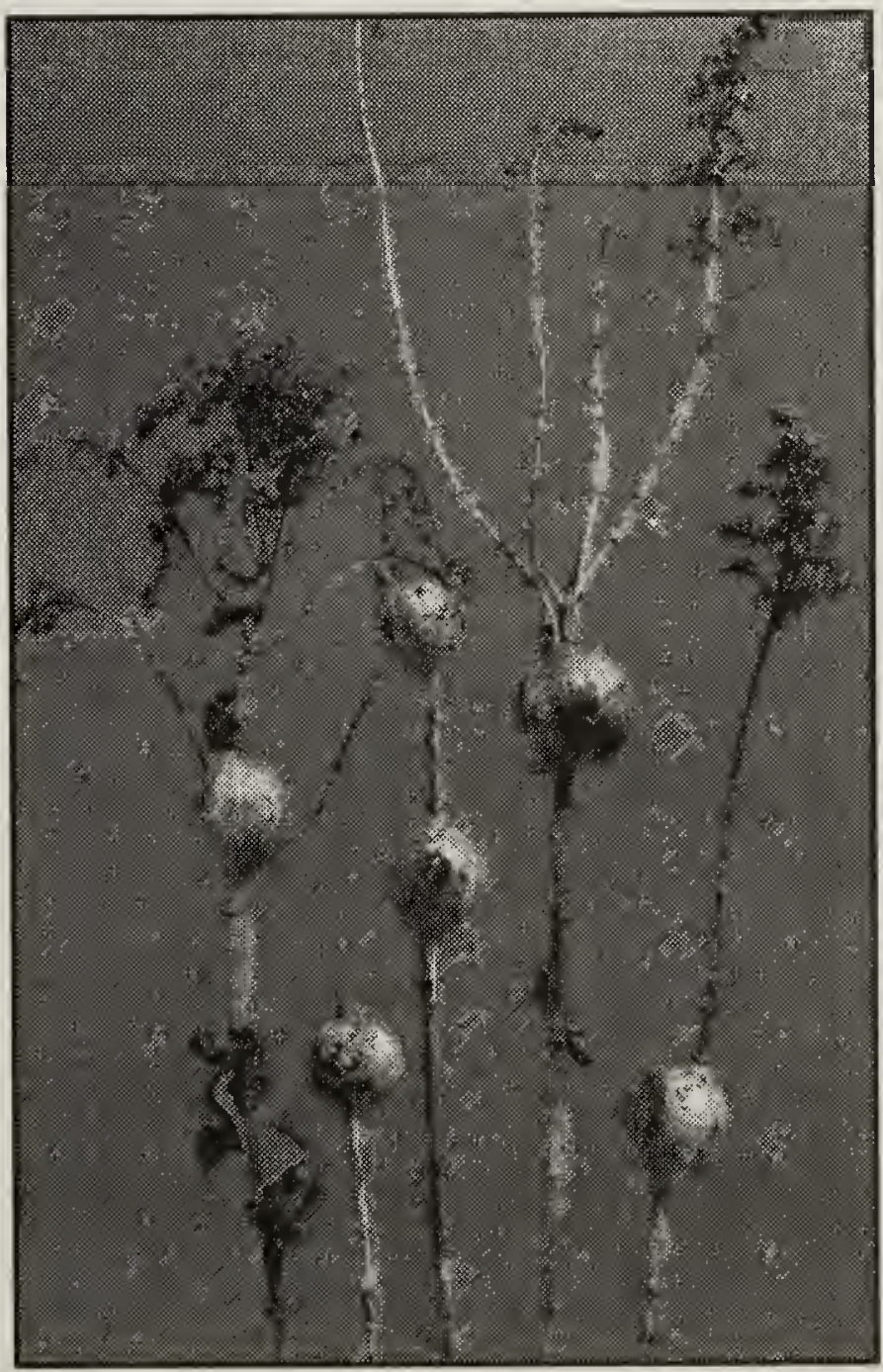

Figure 2. Previous year's galls

Don Buckle from mid-May to early June, depending on seasonal temperatures and local microclimate. The flies are 7 or $8 \mathrm{~mm}$ long, with black patterned wings. The female (Fig. 3) has a stout, strong ovipositer while the male's abdomen is blunt (Fig. 4). The male begins courting within a few hours of emerging and is especially interested in newly emerged individuals whose wings have not yet completely expanded. He will court them enthusiastically regardless of their sex. Like other fruit flies, the male gall fly performs a visual courtship in which he flaunts his patterned wings. In a typical display he stands $5-10 \mathrm{~mm}$ from the object of his affections, bends the trailing edges of his wings downward so that their black patterns are visible, and rocks from side to side twice per second, moving his legs while keeping his wings parallel to the surface. He then moves closer and repeats his display. Eventually, if he has shown

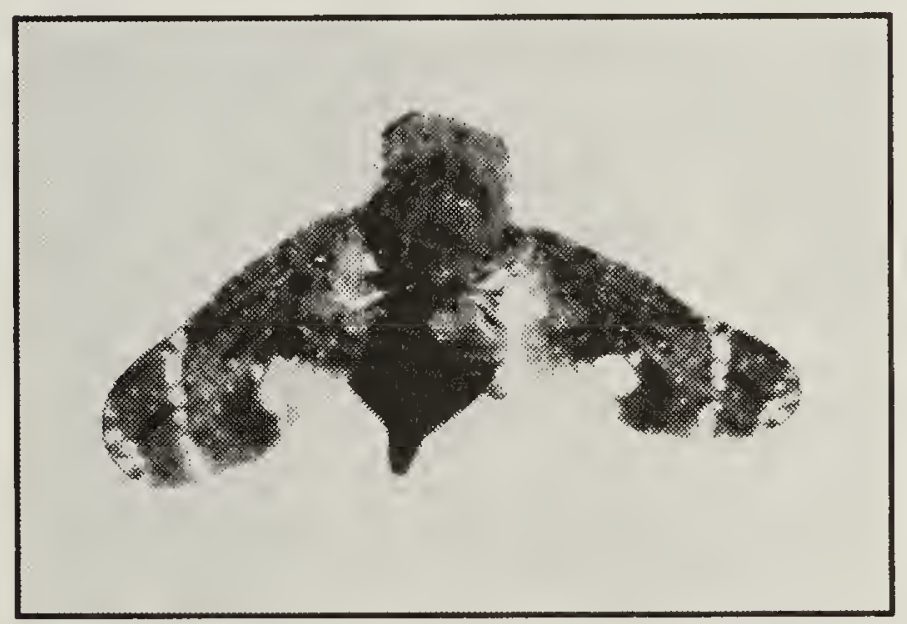

Figure 3. Goldenrod Gall Fly adult. Female Don Buckle

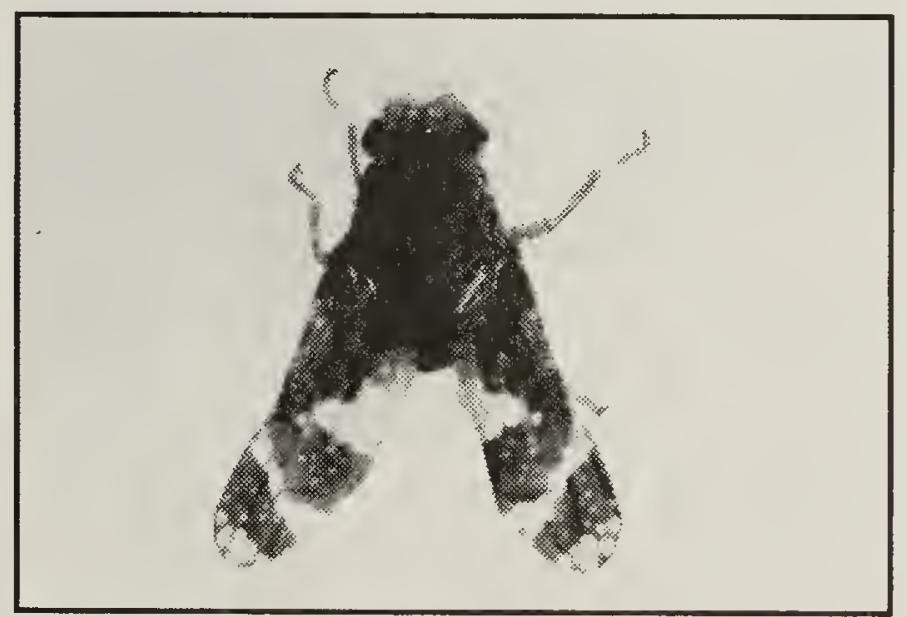

Figure 4. Goldenrod Gall Fly adult. Male Don Buckle 
good judgement and courted a female, mating follows.

After her eggs develop, the female seeks out goldenrod stems in which to lay them. In goldenrod patches with moderate infestations, there is usually one gall per stem, suggesting a female lays one egg then moves to another stem. In heavily infested patches, there may be two, three, or even four galls per stem. I suspect in cases of multiple galls, each is formed from an egg layed by a separate female. The goldenrod stem begins to swell in response to growth hormones secreted by the hatching fly larva. In early June, the gall is spindle shaped and no more than 4 or 5 times the diameter of the goldenrod stem. By mid-August the gall is a fully formed sphere $20-25 \mathrm{~mm}$ in diameter. When opened, it is found to be a hard-walled ball of pith with the larva feeding in its center (Fig. 5 \& 6). Before mid-September, the fully grown larva excavates a tunnel from the center of the gall to the perimeter, leaving only a thin membrane of tissue between it and the outside world. The larva then retreats back to the centre of the gall where it settles in, facing the tunnel, to overwinter. In early spring, by the end of March or early May the larva pupates. Like many other higher Diptera, when the adult fly is ready to emerge from the pupal case, it pumps body fluids into a flexible area of its forehead which inflates like a small balloon. This bursts the pupal case. The fly then moves down the tunnel it prepared as a larva, the previous fall and uses the same technique to break through the membrane blocking the tunnel's end. It then perches on the gall for an hour while its wings dry and expand (Fig. 7). Most emergences from collected galls took place at night.

One might assume that the larva is secure, enclosed within its ball, but this is not the case. A Mordellid beetle lays

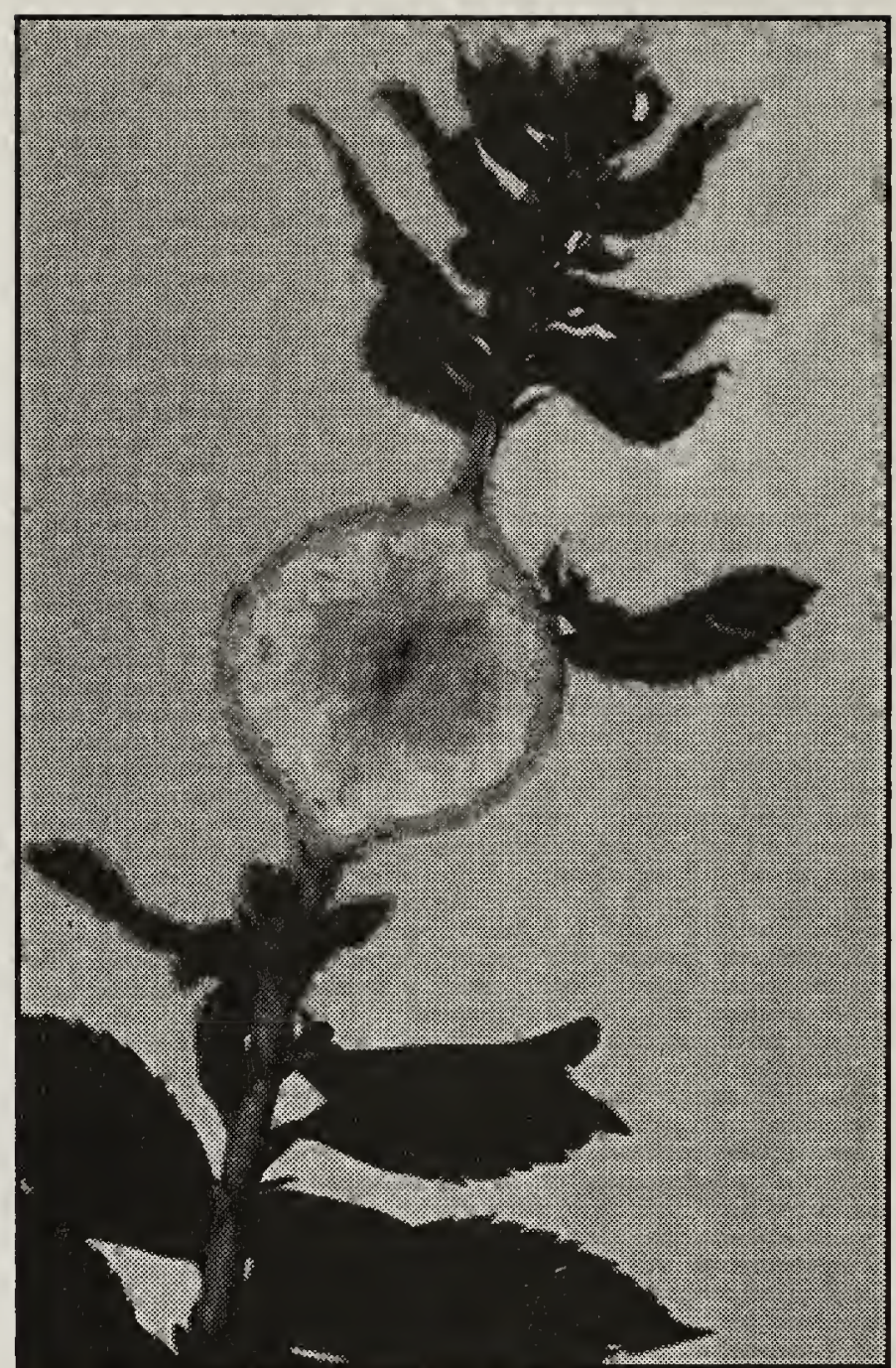

Figure 5. Cut-open gall, 12 August. Don Buckle

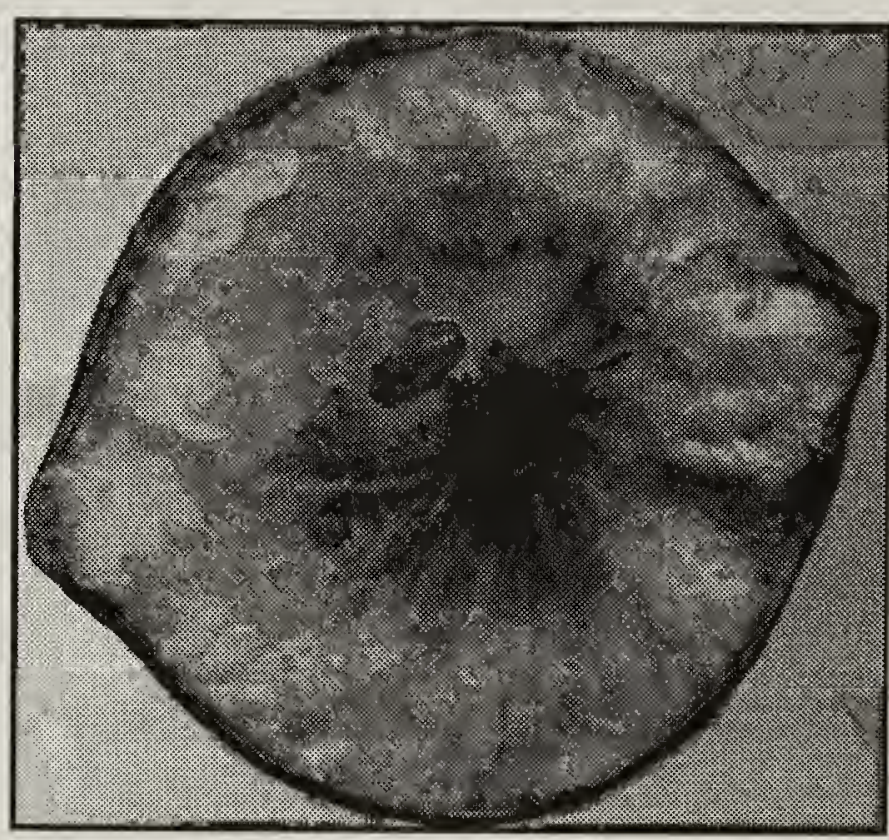

Figure 6. Close up of cut-open gall showing larva, 12 August.

Don Buckle

its eggs in the gall and its larva consumes the gall's tissues and, frequently, the gall fly larva as well. And there are parasites to contend with. The most common is a Eutomid wasp. The female wasp inserts her ovipositer into 


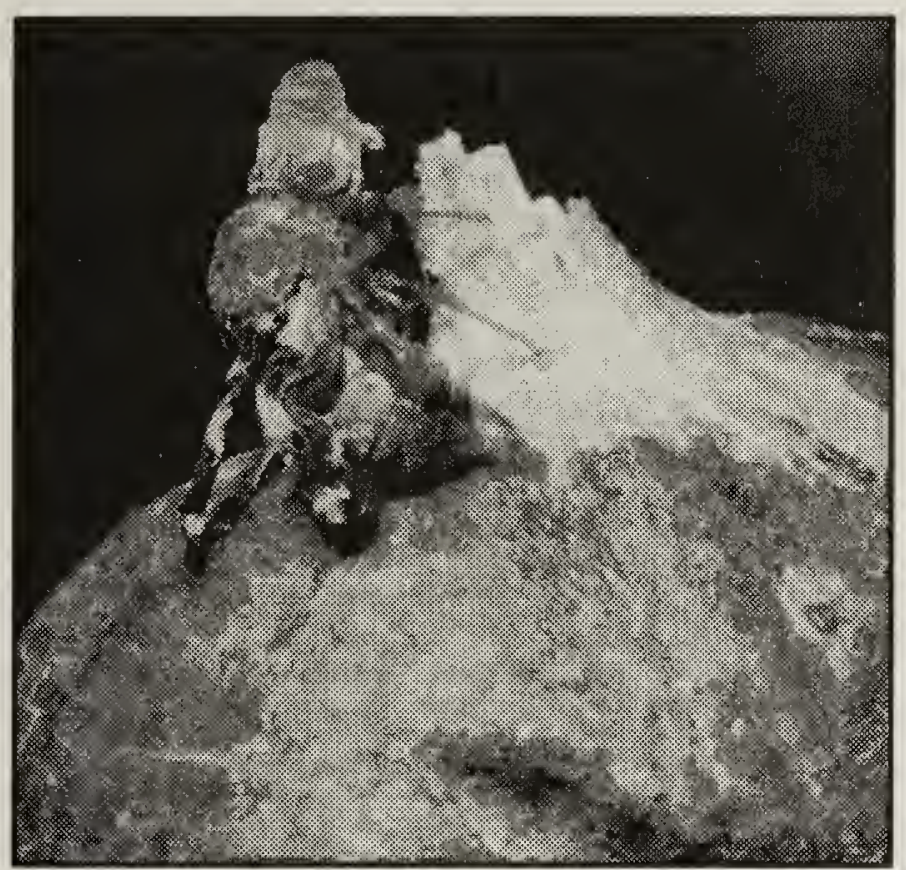

Figure 7. Newly emerged gall fly on goldenrod gall, 14 May.

\section{Don Buckle}

the gall and deposits her egg within the gall chamber where the wasp larva hatches and consumes the gall fly. The wasp emerges in the spring a few days later than the gall flies. This short delay means that the flies will have had time to lay their eggs, and that a new generation of larvae in their developing galls will be available for the wasps. There are predators as well. In an early spring search I found that a significant number of galls had been pecked open by birds over winter (Fig. 8).

Goldenrod galls are made of durable stuff and usually last a second year before disintigrating. The gall fly exit burrows become homes to a variety of small creatures, from tiny caterpillers searching for a secure place to pupate, to baby jumping spiders who line the cavities with silk and make them their homes.

In the years since I dabbled in their biology, goldenrod galls and their inhabitants have been thoroughly studied in Pennsylvania by Dr. Warren Abrahamson of Bucknell University. He has produced a long series of scientific papers on the subject, published a recent book ${ }^{1}$, and created an excellent website: www. facstaff.bucknell.edu/ abrahmsn/solidago.

1. Abrahamson, W.G. and A.E. Weis. 1997. Evolutionary Ecology across Three Trophic Levels: Goldenrods, Gallmakers, and Natural Enemies. Princeton University Press.

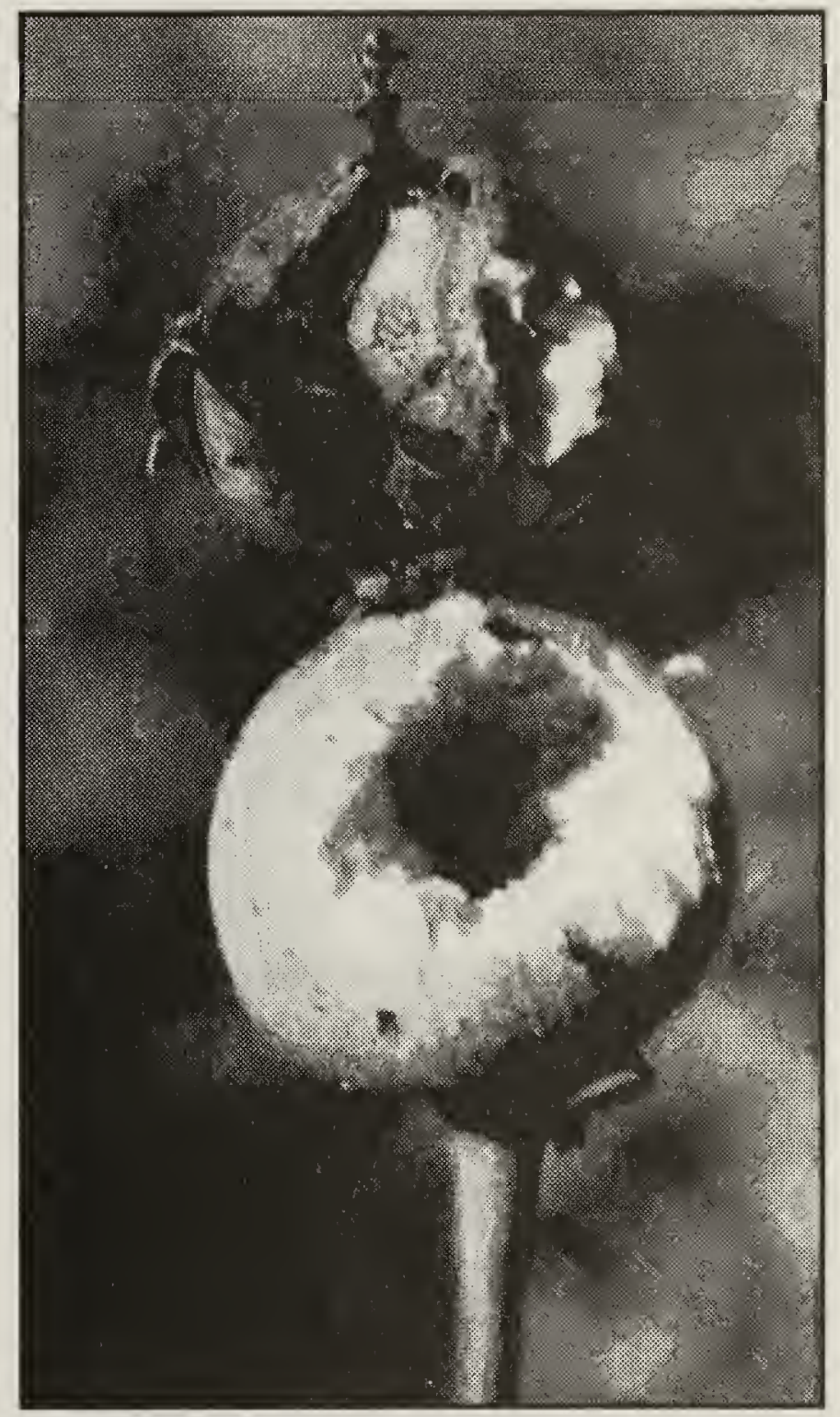

Figure 8. Gall pecked open by birds.

A. Leighton 